malignant process appears to be arrested for a time. A stasis takes place in the activity of the growth. The barometer indicates a steady rise in the health, strength, weight, and activity of the patient. This patient could not have been in a worse possible condition short of death. His prognosis was apparently hopeless, yet 15 months after operation we find him enjoying the best of health, performing a full day's work of the most arduous character, and apparently as well as ever he was in his life. Operative interference in these cases does one of two things, both in themselves desirableit shortens the misery by death or it prolongs the life by recovery.

Harley-street, W.

\section{EOSINOPHILIA ASSOCIATED WITH HYDATID DISEASE.}

By C. G. SELIGMANN, M.B., M.R.C.P. LoND., SUPERINTENDENT OF THE CLINICAL IABORATORY, ST. THOMAS'S HOSPITAL ; AND

L. S. DUDGEON, M.R.C.P. LOND.,

ASSISTANT IN THE ELECTRICAL DEPAR'TMENT, ST, THOMAS'S HOSPITAL.

WE are indebted to Dr. Hector W. G. Mackenzie for permission to publish the following brief notes of a case under his care.

The patient, a well-nourished young woman from the east coast of England, aged 22 years, is one of a family of five children, all of whom, except herself, are stated to be healthy. There is a history of pulmonary tuberculosis on both sides of her family but she herself has always enjoyed good health until two years ago. Before that time she was in the habit of fondling a pet dog which constantly licked her hands. In December, 1900, and again in January, 1901, she suffered from attacks of pain in the right side which were considered to be due to pleurisy. Early in November, 1901, she suffered from abdominal pain which was not severe enough to prevent her following her usual occupation of nursery-maid. On Dec. 20th, 1901, she had malaise and pain in the region of the right shoulder which was so severe that she could not do her work.

On admission into St. Thomas's Hospital on Dec. 24th, 1901 , her temperature was $101 \cdot 2^{\circ} \mathrm{F}$. By the evening of the 26 th it had fallen to normal and remained so till Jan. 10th. There were enlargement of the right lobe of the liver and friction in the right axilla which suggested to Dr. Mackenzie the possible presence of hydatid disease. The patient's blood was examined on Dec. 27th at 11 A.M., about two hours after her last meal and gave the following results : Red cells, 6,290,625 per cubic millimetre; hæmoglobin, 70 per cent.; colour index, about 0.6 ; and white cells, 17,000 per cubic millimetre. A differential count of 500 white cells was as follows: polymorphonuclear neutrophiles, 22 per cent. ; eosinophiles, 57 per cent. ; lymphocytes, 20 per cent. ; and basophiles, 1 per cent.

An operation was performed on Jan. 10th when 10 ounces of clear fluid, which contained hydatid hooklets, were withdrawn from a cyst in the right lobe of the liver. The next day her temperature rose to $102.5^{\circ}$ at midnight and continued to rise to this height nightly with morning remissions until the 18th. A second examination of the blood was made on the 13th. It showed 7000 leucocytes per cubic millimetre. A differential count showed: polymorphonuclear neutrophiles, 58.8 per cent. ; eosinophiles, 12 per cent. ; lymphocytes, 282 per cent.; and basophiles, 1 per cent. On the 16 th it was noticed that the discharge from the cyst was copious and offensive and two days later it was purulent. At this time the temperature became normal for a couple of days; it then rose, and though fluctuating considerably for the next month, it was, on the whole, constantly high at night. Further hydatid cysts were evacuated through an incision in the right fifth intercostal space. A differential blood count was made on Feb. 20th, with the following results : polymorphonuclear neutrophiles, 60 per cent. ; eosinophiles, 1 per cent. ; lymphocytes, 29.4 per cent. ; and basophiles, 0.6 per cent. At this time there was a considerable amount of purulent material draining from both wounds and a few collapsed cysts were also discharged. A blood count taken on March 13th, when the morning temperature was $102^{\circ}$, showed : red cells, 2,934,375, and white cells, 7600 per cubic millimetre. A differential count showed: polymorphonuclear neutrophiles, 73.2 per cent. ; eosinophiles, $3 \cdot 2$ per cent. ; lymphocytes, 22.2 per cent. ; and basophiles, 1.4 per cent. On the 21 st a further cyst was evacuated and a large quantity of clear fluid was withdrawn. On April 3rd the fifth examination of the blood was made when a differential count (200) gave: polymorphonuclear neutrophiles, 64.5 per cent.; eosinophiles, 1 per cent. ; lymphocytes, 34.5 per cent. ; and basophiles, nil. No urticarial rash was present at any stage of the patient's illness.

'The chief interest of the case centres in the high percentage of eosinophiles present. The number found in the first count is in excess of any records which we have been able to find, with the exception of a case of trichinosis under the care of W. Osler, ${ }^{1}$ in which the blood was examined by T. R. Brown and the eosinophiles were found to number 68 per cent. in a total leucocytosis of 1700 , and a case of ankylostomiasis examined by Bücklers, ${ }^{2}$ in which the eosinophiles numbered 72 per cent. It is most nearly approached by certain other cases of trichinosis and in bronchial asthma at the time of the paroxysms. In the latter complaint Billings ${ }^{3}$ reports counts of 53.6 per cent., 38.2 per cent., and 33.9 per cent. eosinophiles in three cases in which the total leucocyte count was not increased. As is well known eosinophilia-for the most part of slight degreeoccurs in a number of diseases, especially, according to Neusser, in pemphigus, in most non-malignant diseases of the liver, and "in trouble involving the female genitals, especially the ovaries." " Further, Neusser considers " that the increase of eosinophiles which he finds in hydatids serves to distinguish them from hydronephrosis, dilated gallbladder, \&c." ${ }^{5}$ Recently Lovell Gulland ${ }^{6}$ has shown that marked eosinophilia occurs in filariasis and his results have been confirmed by Coles ${ }^{\top}$ who, further, in a case of bilharzia disease occurring in an otherwise healthy and athletic Englishman, found that 20 per cent. of the leucocytes present were eosinophiles. None of the causes enumerated above were present in the case which we describe, with the possible exception of ovarian tronble, which might perhaps be considered to have been present since the patient had not menstruated for a few months preceding admission to St. Thomas's Hospital. We do not. however, think that this last-mentioned factor, even considering it to have existed, could have caused the enormous increase of eosinophiles found, and it seems alike simpler and more rational to regard hydatid disease as the cause of the blood change, more especially as the number of eosinophiles present gradually dropped to normal after operation. Again, it is interesting to note that, according to Bückler, " all kinds of helminthides, from the harmless oxyuris to the pernicious ankylostoma, may bring about an increase of the eosinophile cells in the blood, often to an enormous extent." The author makes no mention of hydatid disease.

\section{Clinical A Rotes:}

MEDICAL, SURGICAL, OBSTETRICAL, AND THERAPEUTICAL.

\section{A CASE OF RABIES LATENT FOR 20 MONTHS.}

BY HOWELl REES, L.R.C.P. LOND., M.R.C.S. ENG.,

AND

D. C. Rowlayds, L.R.C.P., L.R.C.S. EdIN.

ON August 9th, 1900, a powerful, mountain-bred man, 63 years of age, was bitten on the metacarpo-phalangeal joints of the thumb and forefinger of the left hand by a fox terrier which hung on to his hand. In his attempts to free himself the wounds were considerably lacerated and were cauterised

1 Osler : Principles and Practice of Medicine, p. 357 (London, 1901) : and Cabot: Clinical Examination of the Blood, p. 289 (London and New York, 1900)

a Quoted by Ehrlich and Loranus : Histology of the Blood, 1900. 3 New York Medical Journal, Mav22nd, 1897.

$$
4 \text { Cabot : loc. cit., p. } 117 \text {. }
$$
Brit. Med. Jour., May 10th, 1902 . 